bệnh tăng huyết áp và NB không được tư vấn với $p<0,000$. Có thể giải thích rằng khi $N B$ đến khám và điều trị ngay từ đầu đã được điều dưỡng giao tiếp rất tận tình được NB hài lòng chiếm $71,4 \%$, kết quả của chúng tôi phù hợp với NC của Bùi Minh Thông nhu cầu cần được chăm sóc của NB chiếm $91,4 \%$, cần được tư vấn sức khỏe rất lớn chiếm tới 80,9\%[7]. Có sư liên quan giữa NB chưa được tư vấn, tốt và NB được tư vấn tốt với tuân thủ điều trị $(p<0,007)$.

\section{KẾT LUÂN}

- Tuân thủ điêu trị của người bênh: về kiến thức: Có kiến thức tuân thủ $(68 \%)$, không (32\%) Về thực hành: có tuân thủ thực hành là $40,9 \%$ và chưa tuân thủ thực hành chiểm $59,1 \%$.

- Một số yếu tố liên quan: Có sự liên quan giữa $\geq 60$ tuổi và $<60$ tuổi với tuân thủ điều trị ( $p<0,05)$; Có sự liên quan giữa nghề nghiệp; giữa nhận biết biến chứng THA; giữa NB mắc kèm bệnh tăng lipit máu; giữa thời gian mắc bệnh > 10 năm và từ $6-10$ năm, giữa kiến thức chưa đạt và NB có kiến thức đạt; giữa thực hành chưa đạt và có thực hành đạt; giữa chưa có thực hiện CS tâm lý và NB được CS tâm lý; giữa không được tư vấn về dinh dưỡng, về tái khám và NB có được tư vấn với tuân thủ điều trị $(p<0,05)$.

\section{TÀI LIÊU THAM KHẢO}

1. Nguyễn Thị Kim Dung và CS (2020), Khảo sát tình trang tăng huyết áp của người bênh ở những ngày đâuu sau ghép thận. Tạp chí Y Dược lâm sàng 108, tập 15, số đặc biệt, tháng 11/2020, tr 142-148
2. Ngô Thị Hương Giang (2013), Kiến thức, thực hành và một số yếu tố liên quan đến phòng biến chứng ở người bi tăng huyết áp tai huyên Thanh Trì, Hà Nội, 2013, Luận văn thạc sỹ, Trường Đại hoc Y tế Công Công.

3. Ngô Vương Hoàng Giang (2020) Thực trạng tuân thủ điêu trị của bệnh nhân tăng huyết áp điều tri ngoại trú tại Khoa Khám bênh, Trung tâm Y tế Huyện Thoại Sơn, An Giang., Tạp chí Y học thức hành, Tâp 31 , số 62021

4. Đố Thị Hiến và CS (2020), Đánh giá sự tuân thủ điều trị ở bệnh nhân tang huyết áp được điều trị ngoai trú tai Phòng khám Nôi Tim mach - Bênh viện Trung ương Quân đội 108, Tap chí Y Dược lâm sàng 108, Hội nghị khoa học điểu dưỡng bệnh viện 2020, tập 15, 11/2020

5. Nguyến Thị Mai và CS (2019), Kiến thức về tăng huyết áp và đái tháo đường của bác sĩ đa khoa công tác tại Trạm Y tế xã ở một số tỉnh miền Bắc., Tạp chí Y học Việt Nam, Tập 4911, tháng 6, số 1, nắm 2020, Trang 64-69.

6. Nguyê̂n Hồng Mînh và CS (2018), Mô tả nhu cầu của người bệnh đến kham tại Khoa Khám bệnh, bệnh viện Trung ương Quân đội 108, quý 1 năm 2018. Tap chí Y Dược lâm sàng 108, Hội nghị khoa học điều dưỡng 2018, tập 13, số đặc biệt 8/2018, trang $300-307$.

7. Bùi Mính Thông và CS (2018), Thực trạng công tác giáo duc sức khỏe cho người bềnh tai bênh viện Nội tiết trung ương năm 2018. . Kỷ yếu Hội nghị khoa học bệnh viện Nội Tiết trung ương mở rông năm 2019. Tir $349-35 \dot{5}$.

8. Phạm Thị Hông Vân và CS (2020), Tìm hiểu kiến thức và thưc hành tuân thủ điều tri của bênh nhân tăng huyểt áp tai Viện Điều trị Cán bộ cao cấp Quân đội. Tap chí Y Dược lâm sàng 108, Hội nghi khoa học điểu dưỡng bệnh viện 2020, tập 15, sổ đặc biệt 11/2020

\title{
KHẢO SÁT Ý KIẾN CỦA NGƯờI BÊNNH ĐỐI VỚI HÊ THỐNG ĐĂNG KÝ KHÁM BỆNH NGOẠI TRÚ TRỰC TUYẾN TẠI KHOA KHÁM BỆNH BÊ̂NH VIỆN ĐẠI HỌC Y DƯợC TP.HCM
}

\section{TÓM TẮT}

Đă̆t vấn đề: Hiên nay tại Việt Nam người bệnh (NB) chủ yếu vẫn sử dụng hình thức đăng ký khám bệnh truyền thống, việc này làm tiêu tốn khá nhiều thời gian và nhân lực cho việc nhận đăng ký, đồng thời không nhận được sự hài lòng cao từ NB và người

${ }^{1}$ Bệnh viện Đại học Y dược TP. Hồ Chí Minh

${ }^{2}$ Trường Đại học Y tế công cộng

Chiu trách nhiệm chính: Thái Hoài Nam

Email: nam.th@umc.edu.vn

Ngày nhân bài: 22.10.2021

Ngày phản biện khoa học: 20.12.2021

Ngày duyệt bài: 27.12.2021

\section{Thái Hoài Nam¹, Hoàng Văn Minh²}

nhà NB. Nhiều nghiên cứu trước đây đã cho thấy rằng lợi ích từ việc đăng kí khám bệnh trực tuyến là vượt trôi hơn so với hình thức đăng ký truyền thống. Do đó việc triển khai áp dụng hê̂ thống đăng ký khám bệnh ngoai trú trực tuyến và tiến hành đánh giá phản hồi của NB tại Khoa khám bệnh tại Bệnh viện là điều vô cùng cần thiết. Muc tiêu: Khảo sát ý kiến của người bệnh đối với hệ thống đăng ký khám bệnh ngoại trú trực tuyến tại k̉hoa khám bênh Bệnh viện Đại học $Y$ Dược TP.HCM. Đối tượng và phương pháp nghiên cứu: Nghiên cứu cắt ngang mô tả, định lượng kết hợp định tính, được tiến hành trên 672 người bệnh từ 18 đển 74 tuổi đến khám ngoại trú tại Khoa khám bệnh thuộc Cơ sở 1- Bệnh viên Đai học Y Dược TP. Hồ Chí Minh trong thời gian từ tháng 1 đến tháng 3/2020. Kết quả: Khoảng 95\% người bệnh hài lòng khi đăng 
ký khám bệnh bằng phần mềm trực tuyến và $75 \%$ cho rằng giá dịch vụ đăng ký là hợp lý. Sau khi đăng ký khám bệnh trực tuyến, hơn 99\% người bệnh muốn giới thiệu hình thức này cho người thân, bạn bè. Kết luân: Mặc dù vẫn còn nhiều khó khăn trong giai đoạn triển khai thực hiện, tuy nhiên hê thống đăng ký khám bệnh trực tuyến đã được đông đảo người bệnh ủng hộ tin dùng. Bệnh viện cẩn đẩy mạnh hoạt động quảng bá hệ thống để mở rộng việc sử dụng hình thức đăng ký trực tuyến này.

Tì̛ khóa: hệ thống đăng ký trực tuyến, đăng ký khám bệnh truyền thống, đăng ký khám.

\section{SUMMARY \\ SURVEY ON PATIENTS OPINIONS ON THE ONLINE REGISTRATION SYSTEM AT THE UMC'S OUTPATIENT DEPARTMENT}

Background: Currently, in Vietnam, patients still mainly use the traditional form of medical examination registration, which consumes a lot of time and human resources for receiving registration, and at the same time does not receive high satisfaction from patients and their family members. Many previous studies have shown that the benefits of the online medical registration are superior to traditional registration. As a result, it is critical to implement the online medical examination registration system and evaluate the patient feedback at the Hospital's Outpatient Department. Objectives: Evaluation of patient knowledge and attitudes during the implementation of the online medical examination registration system at the UMC's Outpatient Department. Methods: Crosssectional descriptive study, quantitative combined qualitative, the study was conducted on 672 patients from 18 to 74 years old who had come for examining at the Outpatient Department of Facility 1- University Medical Center Ho Chi Minh City between January and March of 2020. Results: When registering for a medical examination using online software, approximately $95 \%$ of patients are satisfied, and $75 \%$ believe that the registration service price is reasonable. After registering for an online medical examination, more than $99 \%$ of patients would like to introduce online registration for relatives and friends. Consclusions: Although there are still many difficulties in the implementation phase, the online medical examination registration system has been supported and trusted by a large number of patients. The hospital needs to promote the system to expand the use of this online registration form.

Keywords: the online registration system, Traditional Queuing Method, medical examination registration.

\section{I. ĐĂT VẤN ĐỀ}

Hiện nay tại Việt Nam người bệnh chủ yếu vẫn sử dụng hình thức đăng ký khám bệnh truyền thống (TQM-Traditional Queuing Method), việc này làm tiêu tốn khá nhî̂u thời gian và nhân lực cho việc nhận đăng ký, đông thời không nhận được sự hài lòng cao từ người bệnh (NB) và người nhà NB(1). Nhiêuu nghiên cứu gần đây đã cho thây rằng lợi ích từ việc đăng kí khám bệnh trực tuyến (ORS- Online Registration System) là vượt trội hơn so với hình thức đăng ký truyền thống như giảm các cuộc hẹn sai, cân bằng tải người bệnh, giảm chi phí, tăng mức độ phổ biến, tăng doanh thu, giảm thời gian chờ, cải thiện hiệu quả và giảm tải được nhân viên lao động(8). Bệnh viện Đại học Y Dược Thành phố Hồ Chí Minh (UMC) là một trong những bệnh viện lớn với số lượng bệnh nhân đông và chất lượng dịch vụ hàng đâu cả nước. Từ cuối năm 2018, tại bệnh viện đã triển khai hệ thống đăng ký khám bệnh ngoại trú trực tuyến (Online Registration System- ORS) qua phân mềm trên điện thoại di động hoặc qua website để nhằm giảm thời gian chờ đợi và cải thiện dịch vụ. Nghiên cứu này thật sự rất cân thiết để hỗ trợ công tác tiếp đón NB, tăng chất lượng phục vụ, thực hiện chủ trương lấy NB là trung tâm và giảm quá tải.

Mục tiêu. Đánh giá ý kiến của người bệnh đôi với hệ thông đăng ký khám bệnh ngoại trú trực tuyến tại khoa khám bệnh Bệnh viện Đại họ Y Dước TP.HCM.

\section{II. ĐỐI TƯỢNG VÀ PHƯƠNG PHÁP NGHIÊN CỨU}

Đối tượng nghiên cứu. Người bệnh đến khám ngoại trú tại Khoa khám bệnh thuộc Cơ sở 1- Bệnh viện Đại học Y Dược TP. Hồ Chí Minh trong thời gian từ tháng 1 đến tháng 3/2020.

Tiêu chuẩn chọn: Người bệnh từ 18 đến 74 tuổi, có đây đủ trí lực, tự nguyện đồng ý tham gia nghiên cứu.

Tiêu chuẩn loại trừ: Người bệnh cấp cứu.

Phương pháp nghiên cứu

Thiết kế nghiên cứu Nghiên cứu cắt ngang mô tả, định lượng kết hợp định tính.

Phương pháp thực hiện

- Công cụ nghiên cứu bảo gôm: Bộ phiếu câu hỏi phỏng vấn trực tiếp.

- Quy trình thu thập số liệu: Mỗi ngày sẽ phỏng vấn 30 NB đăng ký bằng ORS và 20 NB đăng ký bằng TQM cùng một chuyên khoa khám được chọn ngẫu nhiên.

Phương pháp thu thập và xử lý số liệu: Số liệu thu thập dựa trên bộ câu hỏi phỏng vấn, lưu trữ bằng phân mềm Microsoft Excel 2020 và phân tích bằng phân mềm Stata 14 .

\section{KẾT QUẢ NGHIÊN CỨU}

Bảng 1. Thông tin về kinh tế - xã hội của người bệnh

\begin{tabular}{|c|c|}
\hline & Cỡ mâu (n=672) \\
\hline \multicolumn{2}{|c|}{ Giới tính } \\
\hline Nữ & $391(58,2 \%)$ \\
\hline Nam & $281(41,8 \%)$ \\
\hline
\end{tabular}




\begin{tabular}{|c|c|}
\hline \multicolumn{2}{|c|}{ Tuối } \\
\hline $18-20$ tuối & $15(2,2 \%)$ \\
\hline $21-30$ tuối & $109(16,2 \%)$ \\
\hline $31-40$ tuối & $121(18,0 \%)$ \\
\hline $41-50$ tuối & $106(15,8 \%)$ \\
\hline Trên 51 tuối & $321(47,8 \%)$ \\
\hline
\end{tabular}

Trong nghiên cứu này, nhóm nghiên cứu đã tiến hành khảo sát trên 672 người bệnh, trong đó $58,2 \%$ là nữ giới, $41,8 \%$ là nam giới; chủ yếu có độ tuổi từ 51 trở lên (chiếm 47,8\%), nhóm tuổi từ 18 đến 20 chiếm tỉ lệ thấp nhất (2,2\%).

Bảng 2. Đặc điểm sử dụng dịch vụ y tế của người bệnh

\begin{tabular}{|c|c|}
\hline \multicolumn{2}{|c|}{ Sồnh thứ̛́c đăng(n=672) } \\
\hline \multicolumn{2}{|c|}{ Hýn khám } \\
\hline $\begin{array}{c}\text { Chỉ đăng ký bằng hình thức } \\
\text { xếp hàng truyên thống }\end{array}$ & $180(26,8 \%)$ \\
\hline $\begin{array}{c}\text { Chỉ đăng ký bằng hình thức } \\
\text { trực tuyến }\end{array}$ & $202(30,1 \%)$ \\
\hline $\begin{array}{c}\text { Lã sữ dụng cả hai hình thức } \\
\text { Lần khám }\end{array}$ \\
\hline \multicolumn{2}{|c|}{$290(43,2 \%)$} \\
\hline Khám lần đầu (khám mới) & $136(20,2 \%)$ \\
\hline $\begin{array}{c}\text { Đã có đăng ký khám trước } \\
\text { đây (người bệnh cũ) }\end{array}$ & $536(79,8 \%)$ \\
\hline
\end{tabular}

Đa số những người bênh đến khám đều đã từng khám trước đó $(79,8 \%)$; có $20,2 \%$ người bệnh đến khám lần đầu. Trong nghiên cứu này, đa số các người bệnh đã sử dụng cả 2 hình thức đăng ký khám là xếp hàng truyền thống và đăng ký bằng hình thức trực tuyến (chiếm tỉ lệ $43,2 \%$ ), bên cạnh đó; $30,1 \%$ chỉ đăng ký bằng hình thức trực tuyến và $26,8 \%$ chỉ đăng ký bằng hình thức xếp hàng truyền thống.

Bảng 3. Kêt quả khảo sát tính châp nhận trên người bệnh

\section{Cỡ mầu ( $n=492)$}

Hài lòng khi đăng ký khám bệnh bằng phần mềm trực tuyến

\begin{tabular}{|c|c|}
\hline Rất hài lòng & $160(32,5 \%)$ \\
\hline Hài lòng & $313(63,6 \%)$ \\
\hline Bình thường & $18(3,7 \%)$ \\
\hline Không hài lòng & $1(0,2 \%)$ \\
\hline Khoản phí dịch vụ phải trả $(10.000$ VND) cho 1 \\
lần đăng ký khám bệnh trực tuyến là hợp lý \\
\hline Có & $369(75,0 \%)$ \\
\hline Không & $123(25,0 \%)$ \\
\hline
\end{tabular}

Về mức phí dịch vụ phải trả (10.000 VND) cho 1 lần đăng ký khám bệnh trực tuyến là hợp, $75 \%$ người bệnh cho rằng là hợp lý, tuy nhiên vẫn còn $25 \%$ người bệnh cho rằng mức phí này còn cao, chưa phù hợp. Khoảng 95\% người bệnh hài lòng khi đăng ký khám bệnh bằng phần mềm trực tuyến, trong đó 32,5\% rất hài lòng; 3,7\% cảm thấy bình thường, có 1 NB không hài lòng với dịch vụ này.

Bảng 4. Kêt quả khảo sát tính tiếp nhận trên người bệnh

\begin{tabular}{|c|c|c|}
\hline & \multicolumn{2}{|c|}{ Cõ mấu (n=492) } \\
\hline & Không & Có \\
\hline \multicolumn{3}{|c|}{ Lợi ích khi đăng ký khám bệnh trực tuyến } \\
\hline $\begin{array}{l}\text { Tiện lợi, đăng ký mọi lúc, } \\
\text { mọi nơi. }\end{array}$ & $\begin{array}{c}66 \\
(13,4 \%)\end{array}$ & $\begin{array}{c}426 \\
(86,6 \%)\end{array}$ \\
\hline $\begin{array}{c}\text { Nhanh chóng, không mất } \\
\text { nhiều thời gian đến xếp } \\
\text { hàng đăng ký tại BV }\end{array}$ & $\begin{array}{c}92 \\
(18,7 \%)\end{array}$ & $\begin{array}{c}400 \\
(81,3 \%)\end{array}$ \\
\hline $\begin{array}{l}\text { Linh hoạt, có thể đăng ký } \\
\text { khám bệnh cho người thân }\end{array}$ & $\begin{array}{c}273 \\
(55,5 \%)\end{array}$ & $\begin{array}{c}219 \\
(44,5 \%)\end{array}$ \\
\hline $\begin{array}{l}\text { Chủ động, chọn khung thời } \\
\text { gian để khám bệnh }\end{array}$ & $\begin{array}{c}149 \\
(30,3 \%)\end{array}$ & $\begin{array}{c}343 \\
(69,7 \%)\end{array}$ \\
\hline $\begin{array}{c}\text { Chọn được Bác sĩ mong } \\
\text { muốn khám bệnh }\end{array}$ & $\begin{array}{c}123 \\
(25,0 \%)\end{array}$ & $\begin{array}{c}369 \\
(75,0 \%)\end{array}$ \\
\hline
\end{tabular}

Khi được hỏi về lợi ích khi đăng ký khám bênh trực tuyến, có rất nhiều yếu tố được người bểnh chọn lựa, trong đó các yếu tố được hầu hết NB lựa chọn gồm: nhanh chóng, không mất nhiêu thời gian đến xếp hàng đăng ký tại $B V$ $(81,3 \%)$; tiện lợi, đăng ký mọi lúc mọi nơi (86,6\%); lựa chọn được BS mong muốn khám bệnh (75\%). Hơn $55 \%$ cho rằng có thể chủ động chọn khung thời gian khám bệnh và có thể đằng ký khám bệnh cho người thân.

Bảng 5. Kêt quả khảo sát tính thích hợp trên người bệnh

\begin{tabular}{|l|r|r|}
\hline & \multicolumn{2}{|c|}{ Cõ̃ mầu(n=492) } \\
\hline & Không & Có \\
\hline
\end{tabular}

Lý do nào Bạn/ Anh/ Chị/ Cô/ Chú/ Bác nghĩ Đăng ký khám bệnh trực tuyến hiệu quả

\begin{tabular}{|c|c|c|}
\hline $\begin{array}{c}\text { Đăng ký nhanh } \\
\text { chóng }\end{array}$ & $74(15,0 \%)$ & $418(85,0 \%)$ \\
\hline $\begin{array}{c}\text { Tiết kiệm được thời } \\
\text { gian chờ đợi khi } \\
\text { khám bệnh (Chi } \\
\text { phí lợi ích) }\end{array}$ & $70(14,2 \%)$ & $422(85.8 \%)$ \\
\hline Thoải mái & $146(29,7 \%)$ & $346(70,3 \%)$ \\
\hline Tiện dụng & $219(44,5 \%)$ & $273(55,5 \%)$ \\
\hline Dề dàng & $175(35,6 \%)$ & $317(64,4 \%)$ \\
\hline Độ chính xác & $32(6,5 \%)$ & $460(93,5 \%)$ \\
\hline Lồi khi đăng ký & $472(95,9 \%)$ & $20(4,1 \%)$ \\
\hline Độ nhạy dữ liệu & $480(97,6 \%)$ & $12(2,4 \%)$ \\
\hline $\begin{array}{c}\text { Giới thiệu đăng ký } \\
\text { khám khám trực } \\
\text { tuyến cho người } \\
\text { thân, bạn bè sứ dụng }\end{array}$ & $4(0,8 \%)$ & $488(99,2 \%)$ \\
\hline
\end{tabular}

Khoảng 99\% người bệnh sau khi đăng ký khám bệnh trực tuyến muốn giới thiệu đăng ký khám khám trực tuyến cho người thân, bạn bè sử dụng. 
Bảng 6. Kêt quả khảo sát tính khả thi trên người bệnh

\begin{tabular}{|c|c|c|}
\hline & \multicolumn{2}{|c|}{ Cỡ mâu (n=492) } \\
\hline $\begin{array}{c}\text { Có thiết bị đế đăng } \\
\text { nhấp hế thống đăng } \\
\text { ký khám bệnh trực } \\
\text { tuyển }\end{array}$ & $7(1,4 \%)$ & $\begin{array}{c}485 \\
(98,6 \%)\end{array}$ \\
\hline $\begin{array}{c}\text { Có nhận được tin } \\
\text { nhắn qua điện thoại } \\
\text { thông báo số thứ tự } \\
\text { khám hiện tại và } \\
\text { thời gian săp đến } \\
\text { lượt }\end{array}$ & $24(4,9 \%)$ & $\begin{array}{c}468 \\
(95,1 \%)\end{array}$ \\
\hline $\begin{array}{c}\text { Gă̆p khó khăn khi } \\
\text { đăng ký khám bệnh } \\
\text { trực tuyến }\end{array}$ & $\begin{array}{c}484 \\
(98,4 \%)\end{array}$ & $8(1,6 \%)$ \\
\hline $\begin{array}{c}\text { Khó khăn Thao tác } \\
\text { sứ dụng }\end{array}$ & $\begin{array}{c}4 \\
(76,16 \%)\end{array}$ & $3(43,86 \%)$ \\
\hline Tra cứu thông tin & $5(71,43 \%)$ & $2(28,57 \%)$ \\
\hline
\end{tabular}

Thời gian từ lúc đăng nhập phần mềm đến khi đăng ký khám thành công

\begin{tabular}{|c|c|}
\hline Dưới 5 phút & $213(43,3 \%)$ \\
\hline $5-10$ phút & $174(35,4 \%)$ \\
\hline $11-20$ phút & $75(15,2 \%)$ \\
\hline $21-30$ phút & $25(5,1 \%)$ \\
\hline Không biết/không nhớ & $5(1,0 \%)$ \\
\hline $\begin{array}{c}\text { Thời gian đến beênh viện trước so với giờ khám } \\
\text { được thông báo khi đănng ký bằng phần mềm }\end{array}$ \\
\hline Khoảng 30 phút & $331(67,3 \%)$ \\
\hline $31-60$ phút & $128(26,0 \%)$ \\
\hline $\begin{array}{c}\text { Hơn } 1 \text { giờ nhưng ít } \\
\text { hơn } 2 \text { giờ }\end{array}$ & $28(5,7 \%)$ \\
\hline Hơn 2 giỡ & $3(0,6 \%)$ \\
\hline Không biết/không nhớ & $2(0,4 \%)$ \\
\hline
\end{tabular}

Từ lúc đăng nhập phần mềm đến khi đăng ký khám thành công, đa số người bệnh mất ít hơn 5 phút để hoàn tất quá trình này $(43,3 \%) ; 35,4 \%$ người bệnh mất từ 5 đến 10 phút; $15,2 \%$ người bênh mất từ 11 đến 20 phút, chỉ có khoảng dưới $5 \%$ người bệnh cho rằng mình mất từ 21 đến 30 phút để hoàn tất quy trình đăng ký này. Khi đăng ký bằng phần mềm, hầu hết người bênh đến bênh viện trước 30 phút so với thông báo (khoảng 67\%), 26\% người bệnh đến trước 60 phút so với thông báo, khoảng $5 \%$ NB đến trước 2 giờ, chỉ có $0.6 \%$ đến sau 2 giờ so với thông báo từ phần mềm đăng ký.

Có khoảng 95\% người bênh đều nhận được tin nhắn qua điện thoại thồng báo số thứ tự khám hiện tại và thời gian sắp đến lượt.

\section{BÀN LUÂN}

Trong thời gian hiện nghiên cứu này, trung bình mổi ngày có 4.190 người bệnh đăng ký khoa khám bệnh bằng hình thức giấy, và có 699 người bệnh đăng ký khoa khám bệnh bằng hình thức trực tuyến. Như vậy tỷ lệ bao phủ là 699/4890 là khoảng 14,3 \%. Mặc dù tỳ lệ là không cao so với các quốc gia khác trong khu vực như Trung Quốc ${ }^{(8)}$, Đài Loan ${ }^{(8)}$, tuy nhiên nểu đánh giá trên tình hình tại Việt Nam thì tỷ lệ này khá cao. Đây cũng là một dấu hiệu khách quan cho việc thay đổi thói quen sử dụng ứng dụng công nghệ thông tin của người bệnh.

Tính chấp nhận. Khi được phỏng vấn về những lợi ích của hề thống đăng ký trực tuyến, đã có nhiều ý kiến tích cực như nhanh chóng và thuận tiện. Chờ đợi được coi là một chỉ số về chất lượng chăm sóc của các dịch vụ và là nguồn gốc của sự không hài lòng có thể ảnh hưởng đến kết quả của chăm sóc y tế(6).

Về mức phí dịch vụ phải trả (10 000 VND) cho 1 lần đăng ký khám bệnh trực tuyến, 75\% người bệnh cho rằng là hợp lý, tuy nhiên vấn còn $25 \%$ người bệnh cho rằng mức phí này còn cao. Tương tự các nghiên cứu khác, mặc dù người bệnh hài lòng với dịch vụ này tuy nhiên họ vẫn không muốn chi trả cho hoạt động này(4).

Tính tiếp nhận. Hầu hết NB cho biết rằng đăng ký khám bệnh trực tuyến diễn ra tiện lợi $(86,6 \%)$, Nhanh chóng, không mất nhiều thời gian $(81,3 \%)$, chọn được Bác sĩ mong muốn (75\%). Theo một nghiên cứu hồi cứu được thực hiện tại một bệnh viện Trung Quốc báo cáo rằng hệ thống đặt hẹn dựa trên web đã giảm tổng thời gian chờ đợi trung bình từ 98 phút xuống còn 7 phút vì bệnh nhân không phải xếp hàng đăng ký( 3 .

Hơn $55 \%$ cho rằng họ có thể chủ động chọn khung thời gian để khám bệnh và có thể đăng ký khám bênh cho người thân. Đây chính là lợi thế nổi bật của hình thức đăng ký qua ứng dụng. Một ưu điểm lớn của việc đăng ký khám chữa bệnh trực tuyến là giúp người bệnh tránh phải tổn kém thời gian cho việc chờ đợi bốc số, đăng ký và làm các thủ tục tại chỗ.

Tính thích hợp Khi được hỏi về lợi ích khi đăng ký khám bệnh trực tuyến, hầu hểt NB lựa chọn gồm: Tiết kiệm được thời gian chờ đợi khi đăng ký khám bệnh tại BV $(85,8 \%)$; tiện lợi, thoải mái $(70,3 \%)$; độ chính xác cao $(93,5 \%)$. Nghiên cứu của tác giả Siddiqui cho thây $55 \%$ cho rằng họ có thể chủ động chọ khung thời gian để khám bệnh và có thể đăng ký khám bệnh cho người thân ${ }^{(5)}$.

Khoảng 99\% người bệnh sau khi đăng ký khám bênh trực tuyến muốn giới thiêu đăng ký khám khám trực tuyến cho người thân, bạn bè 
sử dụng. Nghiên cứu tại Trung Quốc cho thấy rằng lời giới thiệu từ bạn bè hoặc gia đình là cách quan trọng nhất mà bệnh nhẩn sử dụng hệ thống đó(8). Tuy nhiên, NHS 111 trực tuyến người dùng ít có khả năng giới thiệu cho người khác hơn (57\% so với 69\%; $p<0,001)^{(7)}$.

Tính khả thi. Từ lúc đăng nhập phần mềm đến khi đăng ký khám thành công, đa số người bệnh mất ít hơn 5 phút để hoàn tất quá trình này $(43,3 \%) ; 35,4 \%$ người bệnh mất từ 5 đến 10 phút; $15,2 \%$ người bệnh mất từ 11 đến 20 phút, chỉ có khoảng dưới $5 \%$ người bệnh cho rằng mình mất từ 21 đến 30 phút để hoàn tất quy trình đăng ký này. Nghiên cứu tại Dubai chỉ ra rằng dưới $50 \%$ bệnh nhân đăng ký trong vòng khoảng 7 phút $(45,2 \%){ }^{(2)}$.

\section{KẾT LUẬN}

Nghiên cứu của chúng tôi cho thấy nhu câu sử dụng hệ thống đăng ký khám chữa bệnh trực tuyến của người bệnh ngày càng tăng. Điều này mang lại rất nhiêu lợi ích, nâng cao sự hài lòng và chất lượng chăm sóc bệnh nhân. Để phát triển và mở rộng việc sử dụng hệ thống này trong thực tế, các bệnh viện phải tăng cường thúc đẩy nhân lực công nghệ thông tin và đầy mạnh hoạt động quảng bá truyền thông.

\section{TÀI LIÊU THAM KHẢO}

1. Công văn 102/CNTT-YTĐTI ngày 12 tháng 3 năm 2018 của Cuc Công nghế thống tin- Bộ Y tế về việc Tăng cường ứng dụng CNTT tại cơ sở khám bệnh, chữa bệnh: Phần mềm quản lý thông tin bệnh viện (HIS) phải chuẩn hóa toàn bộ danh Mục dùng chung hiện đang sử dụng trong Phần mềm theo danh Mục dùng chung do Bộ $Y$ tế và cơ quan có thẩm quyền ban hành; hoàn thiện Phần mềm HIS có đầy đủ các chức năng đáp ứng yêu cầu quản lý bệnh viện.

2. Aburayya $A$, Alshurideh $M$, Albqaeen $A$, Alawadhi D, Ayadeh I. An investigation of factors affecting patients waiting time in primary health care centers: An assessment study in Dubai. J Management Science Letters. 2020;10(6):1265-76.

3. Cao W, Wan Y, Tu H, Shang F, Liu D, Tan Z, et al. A web-based appointment system to reduce waiting for outpatients: A retrospective study. BMC Health Services Research. 2011;11(1):318.

4. De Lusignan $S$, Mold $F$, Sheikh A, Majeed A, Wyatt JC, Quinn T, et al. Patients' online access to their electronic health records and linked online services: a systematic interpretative review. BMJ open. 2014;4(9):e006021.

5. Jones R, Menon-Johansson A, Waters A, Sullivan A. eTriage-a novel, web-based triage and booking service: enabling timely access to sexual health clinics. J International journal of STD \& AIDS. 2010;21(1):30-3.

6. Thao Thi Nguyen S, Yamamoto E, Thi Ngoc Nguyen M, Bao Le H, Kariya T, Saw YM, et al. Waiting time in the outpatient clinic at a national hospital in Vietnam. Nagoya journal of medical science. 2018;80(2):227-39.

7. Turner J, Knowles E, Simpson R, Sampson F, Dixon S, Long J, et al. Health Services and Delivery Research. Impact of NHS 111 Online on the NHS 111 telephone service and urgent care system: a mixed-methods study. Southampton (UK)2021.

8. Zhang $M$, Zhang $C$, Sun $Q$, Cai $Q$, Yang $H$, Zhang $\mathbf{Y}$. Questionnaire survey about use of an online appointment booking system in one large tertiary public hospital outpatient service center in China. BMC Med Inform Decis Mak. 2014;14:4949. doi:10.1186/1472-6947-14-49.

\section{NGHIÊN CỨU QUY TRÌNH BÀO CHẾ VÀ XÂY DỰNG TIÊU CHUẨN Cơ SỞ CHO CỒN XOA BÓP AN BÌNH TẠI TRƯờNG ĐẠI HỌC Y DƯợC THÁI BÌNH}

\section{TÓM TẮT}

Mục tiêu nghiên cứu: Xây dựng được quy trình bào chế Cồn xoa bóp An Bình, Xây dựng được tiêu chuẩn cơ sở cho sản phẩm. Phương pháp nghiên cứu: Ngâm lạnh, ngâm nhỏ giọt và hòa tan. Địa điểm nghiên cứu: Nghiên cứu được tiến hành tai Khoa Dược - Trường Đại học Y Dược Thái Bình. Đối

*Trường Đại học Y Dược Thái Bình Chịu trách nhiệm chính: Nguyễn Việt Khánh Email: khanhschalke04@gmail.com Ngày nhận bài: 25.10 .2021

Ngày phản biện khoa học: 22.12.2021

Ngày duyệt bài: 30.12.2021

\section{Nguyễn Việt Khánh*}

tượng nghiên cứu: là các kỹ thuật sản xuất Cồn xoa bóp, các chỉ tiêu kỹ thuật khi xây dựng tiêu chuẩn chất lượng của cồn xoa bóp. Kết quả nghiên cứu thu được: quy trình và các bước tiến hành bào chế cồn xoa bóp An Bình, xây dựng được tiêu chuẩn cơ sở cho cồn xoa bóp An Bình.

Tư khóa: Cồn xoa bóp An Bình

\author{
SUMMARY \\ STUDY OF PREPARATION PROCESS AND \\ DEVELOPMENT OF BASIC STANDARDSFOR AN \\ BINH MASSAGE ALCOHOL AT THAI BINH \\ UNIVERSITY OF MEDICINE AND PHARMACY
}

